\title{
Vessel Traffic Services (VTS) and e-Navigation to safely and efficiently connect Regions
}

\author{
Gianiti Claresta $^{12}$, Michael Baldauf ${ }^{2}$ \\ ${ }^{1}$ Department of Marine Engineering, Faculty of Marine Technology, Institut Teknologi Sepuluh Nopember, Surabaya 60111, Indonesia \\ ${ }^{2}$ Hochschule Wismar University of Applied Sciences: Technology, Business and Design, Warnemünde, Maritime Simulation Centre \\ Warnemünde, 18119, Germany
}

\begin{abstract}
Vessel Traffic Services (VTS) are shore-based systems to ensure safe and efficient flow of shipping along coast lines and from and to ports. They are standardized and regulated by United Nation's International Maritime Organization (IMO) with major contributing work from International Association of Marine Aids to Navigation and Lighthouse Authorities (IALA). VTSs serve as an additional safety barrier by contributing to the avoidance of maritime accidents and incidents. In the era of digitalization and automation shore-based services are becoming increasingly popular and an important tool to protect the marine environment. The Straits of Sunda divides the region of Western Java and Sumatra island. The straits serving national and international shipping and are characterized by high traffic density in its coastal waters, including crossing passage of the national heaviest ferry traffic. Consequently, it is one of the major safety concerns in Indonesia. Four accidents of ships' collision, grounding, and fire on board have been recorded in the area from 2011-2019 as officially reported by the national safety committee (KNKT). At the same time, VTS provides valuable services to mariners. The implementation of operational standards that comply with international rules and regulations, such as IMO Resolution A.857(20), and IALA Guideline 1111, should be further developed to benefit from the broader set of VTS function. A basic marine engineering study has been done to investigate the roles of Merak VTS implemented at Sunda Strait using German VTS operation as sample cases. In this respect, empirical studies were used to collect primary qualitative data and analysis of secondary data concerning the aspects of human element, the technical and administrative work. The research is to investigate how Merak VTS could potentially improve its contributions to traffic safety and in what way the new routeing and the mandatory ship reporting systems can be integrated to ensure positive effects. The outcome of first basic studies suggests that well adapted procedures, proper equipment, and especially well-trained VTS staff may provide a huge potential to further improve as well as optimize the operation of Merak VTS.
\end{abstract}

Keywords: Vessel Traffic Services, Sunda Strait, IMO, IALA, Qualitative Research, Human Element, Maritime Safety

\section{Introduction}

1.1 Shore-based support for Shipping - the development of VTS

World Trade is one main source of all developments of human lives and societies. Shipping is considered as the blood of world economy. According to [1] and [2] ninety percent of all goods are carried by ships via the several searoutes crossing the oceans and connecting regions. Safety and security are the overarching needs for an efficient and smooth flow of vessel traffic, especially in sea areas with high density of vessels of crossing searoutes. Originally, shore-based services were established to minimize delays and to ensure continuous traffic flow from and to the ports and harbours located some miles inside 
and away from river estuaries. Radar-based assistance was given to vessels off the coast and developed into vessel traffic services (VTS). It became obvious that such shorebased services may also be used as risk management tool, i.e. to reduce the number of accidents and minimize potential connsequences of hazardous events. The concern that a disaster might happen in approaches and port areas itself, furtherly expanded the use of shore-based radar surveillance and carefully organizing traffic flow to avoid potentially dangerous encounters of ships in inconvenient sections of fairways and sea areas [3].

On the other hand, usually, ship routing systems such as Traffic Separation Schemes (TSS) and recommended routes respectively, Ship Reporting Systems are being introduced to address safety concerns of coastal states. Finally, as one component of the maritime transportation system in port approaches and coastal traffic zones, VTS systems were introduced to support smooth traffic flow [5].

VTS are mainly established in national waters in order to protect the marine environment of a coastal state by monitoring vessel traffic and sending out information, warning, and advice or even instruction in case a developing risk or an existing danger has been recognized by an operator in a VTS centre. Nowadays, besides VTS, so called Fleet Operation Centres (FOC) are increasingly introduced. FOCs are operated by shipping companies to monitor vessel traffic, but they are specifically established to exclusively observe the safe and efficient progress only those ships belonging to the own company's fleet. However, so far, no guidance or procedures how to handle any potential relations between the VTS of a coastal state and a FOC of a worldwide operating shipping company exist yet [6].

In recognizing the ultimate value of VTS in managing of potentially high-risk geographic areas and protection of the marine environment, IMO has taken over to provide the legal frameworks for VTS operation. IMO's International Convention for the Safety of Life at Sea (SOLAS 1974), provides basics of VTS standards, rules and regulations for worldwide harmonized VTs operations. Masters of ships and officers of the watch respectively can expect a minimum level of similar procedures for interventions of any VTS into vessel traffic. SOLAS Chapter V: "Safety of Navigation" provides the foundation of when and it what way to implement a VTS and offers regulations as practical guidance for ships owners, crews and others to participate in IMO-recognized VTSS. The use of VTS can only be mandatory in territorial waters and shall follow guidelines as laid down in Resolution A.857(20) adopted by IMO. This resolution requires that any VTS shall have facilities allowing to interact with the traffic and respond to traffic potentially dangerous situations developing in the VTS area. The presently valid VTS guidelines differ between three main types of services:

- Information Service (INS),

- $\quad$ Navigational Assistance Service (NAS) and

- $\quad$ Traffic Organization Service (TOS).

Each of which has specific functional and operational characteristics. Moreover, IMO also describes also criteria for VTS, as well as for qualifications and training of VTS operators. Often reference is made to more detailed guidelines and recommendations developed by the International Association of Marine Aids to Navigation and Lighthouse Authorities (IALA).

However, after more than twenty years of further technical and Technological developments this existing resolution is under revision by IMO [7].

Any IMO recognized VTS is providing information to vessels in the monitored area, by broadcasting via VHF radio or on demand of an individual ship.

\subsection{VTS and e-Navigation}

Currently, among others, there is a rapid increase of digitalization and automation in the maritime domain. The so-called e-Navigation concept is introduced by IMO. ENavigation is commonly defined as the "harmonized collection, integration, exchange, presentation and analysis of marine information on board and ashore by electronic means to enhance berth to berth navigation and related services for safety and security at sea and protection of the marine environment". E-Navigation focuses on better and more comprehensive support of the human operators. However, modern Information and Communication technologies (ICT) are not only core to the implementation of this concept but provide a solid platform for automation of maritime systems. The progressing digitalization further pushes ahead applications of integrated and automated systems to steer even large sea-going ships. However, e- 
Navigation is aiming at more comprehensive and reliable support of the human operators on board and ashore by using electronic means. IMO member states are convinced, that the implementation of this concept substantially may contribute to improve and allow more strategic sea traffic management from ashore [8]. A collateral effect of the eNavigation activities is the combination of digitalization and automation which supports the introduction of autonomous navigation and even unmanned ships. ENavigation provides a perfect infrastructure for sophisticated automation on board and enhanced data communication between ship and shore of all the private and public service providers including VTSs.

\subsection{Implementing VTS and e-Navigation in Indonesia}

Indonesia is operating numerous VTSS and joins the development and implementation of the e-Navigation concept as well.

According to the Indonesian Directorate General of Sea Transportation (DGST) report released in 2018, significant traffic density that serves national and international shipping with crossing passage of the heaviest ferry traffic in Indonesia is the major concern in the Sunda Strait area. There have been collaborative actions between Indonesia and IMO to ensure the safety of navigation and to reduce the number of ship collisions by adopting the TSS and mandatory Ship Reporting System (SRS) [9]. On the other hand, the ecological, social, economic, cultural, scientific, and educational value, as well as international shipping traffic, are on the ascendency in the Baltic Sea area. According to the Baltic Marine Environment Protection Commission guide published in 2016, there have also been collaborative actions by coastal countries of the Baltic Sea to ensure the safety and efficiency in the Baltic, e.g., in regards to winter navigation and to protect the marine

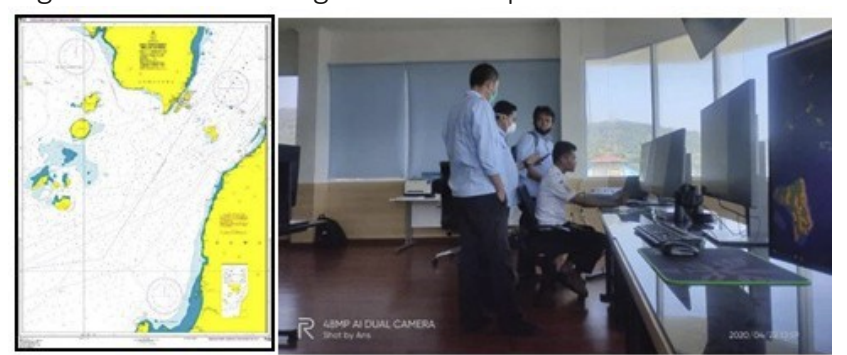

Figure 1: Overview of Sunda Strait (Source: Pushidrosal Navy) and VTS operators at work in Merak VTS. environment by adopting TSSs, deep-water routes, recommending pilot support, mandatory SRS, and particularly sensitive sea area [10].

The research presented in this paper takes into account all those mentioned developments basically by referring to two previous studies, firstly, Praetorius: "Vessel Traffic Service (VTS): a maritime information service or traffic control system?" [5] and secondly Kuma: "Vessel traffic service as a maritime security tool: vessel traffic management information systems (VTMIS) in Ghana" [11]. The first study mainly addresses the everyday performance of the VTS system, especially how to increase and identify its service modeling. Meanwhile, the second study mainly discussed the contribution and capabilities of VTS, the shortfalls of its use and ways to overcome. The difference related to the research focusing on Sunda Strait aside the location, is that the previous studies did not analyze primarily based on the rules and recommendations.

Therefore, this study is more focusing on the implementation of rules in the operational procedures, functions, and technical equipment of VTS.

Sunda Strait where, among others, is characterized as a congested crossing lane. The hydrography chart of the Sunda Strait showing Merak and Bakauheni is presented in Figure 1, which has become the monitoring area of Merak VTS in Indonesia $[12,13]$. Recently, three accidents have been recorded in the area with some fatal accidents of ships' collision and grounding from a total of 101 accidents in Indonesia between 2007-2018 [14]. In comparison with Sunda Strait in the same period, the whole Baltic Sea had six accidents from the total of 105 accidents in Germany caused by ship's collision, grounding, fire on board, and foundering. As depicted in Figure 2, Warnemünde VTS is covering vessel traffic in southern Baltic Sea area with its related ports [15].

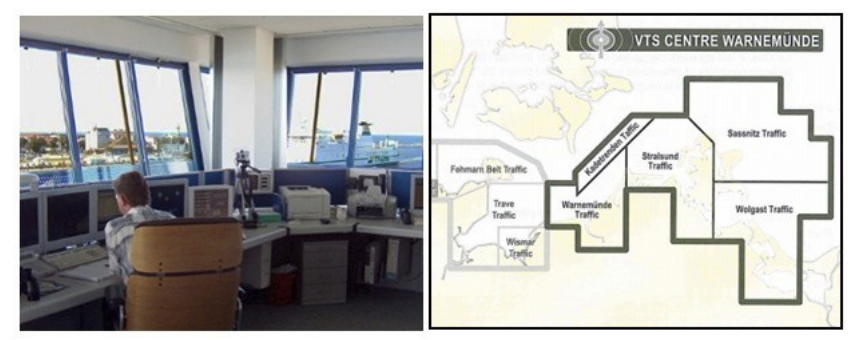

Figure 2: Snapshot from VTS Warnemünde and schematic presentation of areas and sectors of Warnemünde VTSC. (Source: VTS Guide Germany, No. 2011, BSH, 2018). 
Earlier studies obtained fleet data containing the composition of ship traffic from recorded AIS messages, as well as the fleet of ferries from ASDP Company. The recapitulated data in 2017 showed 47,575 vessels sailing in the Sunda Strait area showing some regular and irregular lanes of vessels. In 2019, there were 7,255 passengers and 767,582 tons of goods transported between islands by ASDP Company in which ports of Merak and Bakauheni play as two of the main ports with the highest contribution. They currently manage 35 ports, 246 routes, and 152 vessels through 29 locations nationwide Indonesia, exclusively two routes from Merak to Bakauheni with one port and nine ships.

Fundamental research for considering the establishment of routeing measures and ship reporting systems in Sunda Strait has been conducted by Sunaryo et al. [16] and Sobaruddin et al. [19]. Moreover, the official document of the proposal for the establishment of the routeing system has been submitted to IMO through NCSR 5th session [17]. Though, the research with a focus on everyday performance to highlight the service contribution to the safe navigation of vessel traffic within VTS approaches has not been conducted yet. That is why this study is significant and helping to understand better, how the optimal design, installation, and operation of Merak VTS potentially can more efficiently contribute to safety, efficiency, and sustainability of maritime traffic.

Establishing a VTS is usually a very complex process of implementing, optimizing, adapting and tuning technical components and takes into account the human element. The development and implementatition of operational procedures specifically drafted to ensure smooth interactive functioning of these elements are essential for this. Using the VTS for Sunda Strait in Merak and South Baltic VTS Centre in Warnemünde as a baseline, the ongoing study is to compare the operations of the two VTSs. The study aims at identifying potentials for improvement and optimization of operations in Merak VTS.

\section{Baseline Studies for Comparison}

First pilot studies have been carried out in order to benchmarking the guidance of IMO Resolution A.857(20) and IALA Guideline 1111 into the implementation of Merak
VTS to monitor the vessel traffic in Sunda Strait. After figuring out the level of compliance with rules and regulations, the further study discusses the preliminary outcome of empirical investigations and elaborates on a case study, similarities, and differences between Merak VTS and Warnemünde VTS to identify areas with potential for improvement.

For the research in this study, data were collected from both primary and secondary sources. The primary data were collected through own participating observations and interviews. Meanwhile, the secondary data used are Standard Operational Procedures of Merak VTS by DJPL [13], VTS Guide Germany by BSH [15], the IMO Resolution [4], the IALA publications [3, 18], and literature [5, 21-23]. The rules from each regulation were categorized into three aspects to gain preliminary study and do further study afterward on the developed essential issues. The defined aspects are explained as below:

- Technical aspect contains all rules from chosen regulations in terms of technology and equipment.

- Human element's aspect contains all rules from chosen regulations in terms of staff recruitment, skills, and training.

Administrative work's aspect contains all rules from chosen regulations in terms of procedures and responsibilities of Competent Authority.

The benchmarking has been accomplished by analyzing the Standard Operational Procedure (SOP) of Merak VTS, doing study visits, also conducting informal conversational interviews with Head of Merak VTS and the experts in the same VTS. The compliance with regulations was studied by providing implementations level within three categories and criteria, whether each of the rules has been "fully complied", "partially complied", or has "not been complied at all".

The IALA Guideline 1111 has not been mentioned nor adopted by Merak VTS on its SOP. Meanwhile, the Ministry of Indonesia adopted the IALA Recommendation V-128 as the standard of equipment for all VTS in Indonesia [22]. Nevertheless, this recommendation recognizes and refers to the IALA Guideline 1111 as the updated version and information for VTS systems. The guideline addresses the relationship between operational and technical 


\begin{tabular}{|c|c|c|}
\hline Technical & Human Element & Administrative Work \\
\hline $\begin{array}{l}\text { - General considera- } \\
\text { tion for VTS }\end{array}$ & $\begin{array}{l}\text { - General considera- } \\
\text { tion for VTS } \\
\text { - Objectives and } \\
\text { authority } \\
\text { - Framework } \\
\text { - Prerequisites for } \\
\text { the system } \\
\text { - System parame- } \\
\text { ters: Recruitment } \\
\text { and selection, } \\
\text { qualifications, } \\
\text { training, certifica- } \\
\text { tions }\end{array}$ & $\begin{array}{l}\text { - General considera- } \\
\text { tion for VTS } \\
\text { - Guidance for plan- } \\
\text { ning and imple- } \\
\text { menting VTS } \\
\text { - Determining skill } \\
\text { and knowledge } \\
\text { requirements asso- } \\
\text { ciated with VTS } \\
\text { functions }\end{array}$ \\
\hline $\begin{array}{c}\text { (Covered } 4 \% \text { of all } \\
\text { rules) }\end{array}$ & $\begin{array}{c}\text { (Covered } 54 \% \text { of all } \\
\text { rules) }\end{array}$ & $\begin{array}{c}\text { (Covered } 42 \% \text { of all } \\
\text { rules) }\end{array}$ \\
\hline
\end{tabular}

Table 1: Overview Regulated Rules of IMO Resolution A.857(20).

performance requirements for VTS equipment. It presents system design, sensors, communications, processing, and acceptance, without inferring priority of VTS equipment [21]. The regulated rules subtracted for each of the three aspects is presented in Table 1, exemplarily.

Furthermore, a series of study visits to Merak VTS in Indonesia, as well as the Maritime Simulation Centre Warnemünde (MSCW) and Warnemünde VTSC in Germany has been carried out in order to looking for different approaches and intentions. Beside participating observation, we also conducted interviews on the phone and face to face meetings to develop essential issues from the conducted preliminary study. The study intended to investigate how is the implementation level of VTS by compliance with rules and regulations; to identify training scheme and operational procedures; to identify VTS capabilities in increasing maritime safety through navigation in the area, and derive recommendations for the identified potentials of the system. The main questions that were used for the interviews in both VTSS and the detailed version of the questions, which is guided by a questionnaire form, were provided and elaborated in the frame of this research project [20].

\section{Selected Results}

\subsection{Compliance with IALA Guideline 1111}

As technical issues becoming the focus of our research, this guidance is significant because it is clearly linked to VTS for most of the technical aspects. From the study, the graph compliance of the technical aspect in Merak VTS presented several levels of implementation. However Figure 3 shows that most of the implementation of the technical aspect is fully complied with the rules, as much as $61 \%$ of compliance.

It is followed accordingly by $33 \%$ and only remaining $6 \%$ of the rules have been partially complied and not complied at all. Besides the technical aspect, implementation of administrative work and human element aspect in Merak VTS have $13 \%$ and $50 \%$ of full compliance with all rules in each aspect accordingly. Despite the lower full compliance compared with another aspect, the aspect of administrative work has $88 \%$ of partial compliance.

Some elements which detected to be not complied with this guideline are the environmental protection system, long-range identification and tracking (LRIT), satellitebased synthetic aperture radar (SARSAT), few of intersystem data exchange as part of the VTS data management, and trackwarning for air draught clearance as a function of decision support tools.

The environmental protection system requires the early detection sensors or software processing of the VTS radar signal to detect any pollution incidents that may be caused by visiting vessels. Meanwhile, the LRIT and SARSAT are the long-range sensors for locating or detecting vessels that
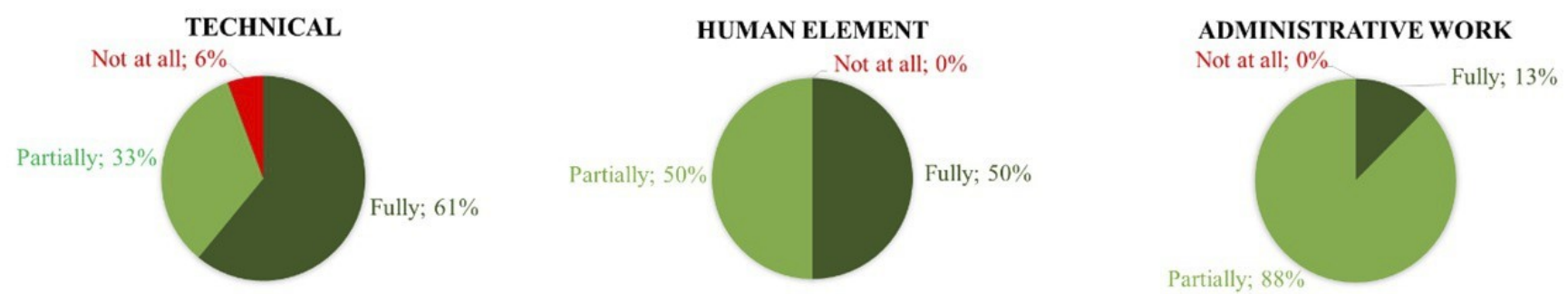

Figure 3: Technical, Human Element, and Administrative Work's Compliance with IALA Guideline 1111. Note: Score of 100\% defines the particular aspect that has been entirely in accordance with this guideline. 
have not arrived on schedule, arrive unannounced or even in case of an incident. According to this guideline, the tracking function and other data processing functions may need to be considered within the VTS design. Data processing is the collection and extraction of data to provide information. This VTS data management may include information such as voyage data, vessel data, incident data, and equipment fault records. The identified missing elements are the information of the data of berths and capabilities, traffic analysis data, and VTS spares and consumables stock.

The mentioned elements in this preliminary study were found to be not yet installed and were identified as not complying with the rules of IALA Guideline 1111. However, the upgrade and installation of such technical equipment to improve the compliance were on progress.

\subsection{Implementation Level of VTS by Compliance with Rules and Regulations}

According to the preliminary study, Indonesia, through the services of Merak VTS, has a relatively high compliance in the terms of human element and administrative work.

However, the technical aspects have shown the lowest compliance compared to others. Therefore, this section interprets the preliminary outcome of empirical study and discusses the aspects of rules and regulations governing the technical issues of system of Merak VTS.

The interviews found that the Merak VTS operators are trained according to the basic course for navigating vessel traffic through VTS area, which is the basic training as VTS operators according to the IALA VTS 103 Modules, the communication competency training according to the IMO Standard Marine Communication Phrases (SMCP), as well as the maritime radio communication training of GMDSS's General Operators Certificate (GOC) in accordance with the IMO. Though, the personnel who is a contracted employee had only been formally taken through the training of GMDSS GOC.

The Merak VTS is expected to be regulated by the requirements of the IMO. The IMO legislations such as in SOLAS Chapter $V$ in regulation 12, guidelines contained in the Resolution A.857(20), MARPOL, and COLREGs. To carry out the duties as VTS personnel, they refer to the SOP of Merak VTS as the operational guide.

The participants of Merak VTS were all able to give a general structure of the nature of vessel traffic in the Sunda Strait area. Merak VTS covers one sector for the entire area of Sunda Strait from Java Island to Sumatera Island. Merak VTS monitors all vessels, the crossing route for the ferries and passing routes for all vessels. The ferries across the strait and connect the port of Merak with the port of Bakauheni in a day. The operation of the ferries had been monitored by the ferries company, namely ASDP Indonesia Ferry. Nevertheless, Merak VTS keeps on this monitoring. Although there is an available VTS near Bakauheni, namely Panjang VTS, communication between the VTSs had rarely been made.

All participants had been continuously made the coordination with some government agencies, which are port state control, port company, sea and coast guard, water police, Navy, search and rescue team, a port operator and agent, as well as the pilotage. The coordination has been done cooperatively and right in time to minimize the consequences of danger and prevent such an accident from being happened.

The core activities of Merak are monitoring and informing traffic, as defined for the INS of VTS. The VTS personnel can not actively organize the traffic and needs to rely on support from other services, such as the pilot service. It seems like there is no strict enforcement or fine is charged to the particular vessel when any non-compliance has been registered by VTS.

The interviews revealed that the Merak VTS staff has the basic infrastructure necessary for conducting decent surveillance on safety and maritime security in the Sunda Strait area. The communication devices installed in Merak VTS is VHF radio for communicating with vessels. The sensors available consisted of long-range camera, radar, and radio direction finder. These devices were installed on Merak VTS, Cipala Hill, Tempurung Island, and Cikoneng Lighthouse.

Currently, several types of equipment are planned to be installed for full operation, which are i.a. AIS base station, long-range CCTV surveillance, weather sensor, additional workstation units, VHF radio, and generator. At the time of the study, the weather forecast was taken daily from the 
Indonesian Weather Forecast. Some of the existing equipment would also be changed or upgraded, such as the VTS software with alert systems, radar, medium-range CCTV surveillance, and power supply. This equipment is intended to repair or maintain the quality of existing equipment and to fully support the implementation of TSS in Sunda Strait in 2020. Moreover, Indonesian government plans to carry out an electronic pilotage (E-Pilotage) for four of Indonesian sea areas, However, Merak VTS is not yet included but may benefit from experiences gained during operation of E-pilotage.

\section{Training Scheme for VTS Staff}

According to the Resolution A.857(20), the competent authority should specify the level of skill and knowledge a VTS operator must have based on the background and prior experiences and should also consider the training requirements regarding the tasks to be performed. Authorities should be aware of the provided training by considering the prior qualification, skills and knowledge of the VTS staff in order to reach an equivalent skill and knowledge.

The applicable minimum qualification when entering the Merak VTS is having a formal education background in high school degree or equal, having two years of work experience, and ability to communicate in the English language before serving as VTSO. All of the study's participants have a high school or a higher degree, such as diploma degree or bachelor degree, and also have taken GMDSS's GOC before becoming a VTSO. Based on the interviews, all participants of Merak VTS had not had a mariners background. Most of them had a qualified civil servant background, which is Civil Servant Echelon II/b. In case of not having work experience prior to the recruitment process, this qualification is compensated as long as the person has graduated from a higher degree and has been accepted as a civil servant.

On the contrary, the German Authorities set comparably higher qualifications for its personnel to become the operator. All of the VTS staff had to have a mariners' background, have taken GMDSS's GOC and show their certificates prior to the recruitment of VTS staff. Therefore they have experiences sailing on board as the deck officer or equivalent according to the STCW. They also had to have graduated from a technical college for becoming an operator. Meanwhile, they had to have a university of applied science degree to become a supervisor. As for the language, the VTS staff had to have a basic command of the English language for VTSO and good command of the English language for becoming a VTS supervisor.

The stud in Germany shows that having a mariner's background is essential for any VTS staff. The personnel would have the intuition to the best practice of operation on board of a ship, what is needed in a specific sit, and how to manage such a situation in the monitored navigational area. Therefore, they have better focus and more goal-objective oriented to achieve the safety of the maritime traffic.

As identified by the expert interviews, the training system level in Indonesia is different from the IALA VTS 103 modules and could be provided by the government agency or the third party. Most of the time, the training offered to Merak VTSO is part of the BP2TL program, which was established by the Ministry of Research, Technology and Higher Education in Indonesia. The training for VTSO consists of a maritime English course, basic VTS course for 30 days, and a VTS operator course for 40 days. However, the VTS staff has to come into the selection phase to participate in such trainings.

On the other hand, the VTS staff in Warnemünde VTS Centre needs to have participated in a maritime English course, On the Job Training and VTS Operators Training according to IALA V-103 modules. All personnel also had to participate in the refresher training of $\mathrm{V}-103 / 5$ once every two years to memorize the knowledge, especially the necessary skills during unusual operation situations. In

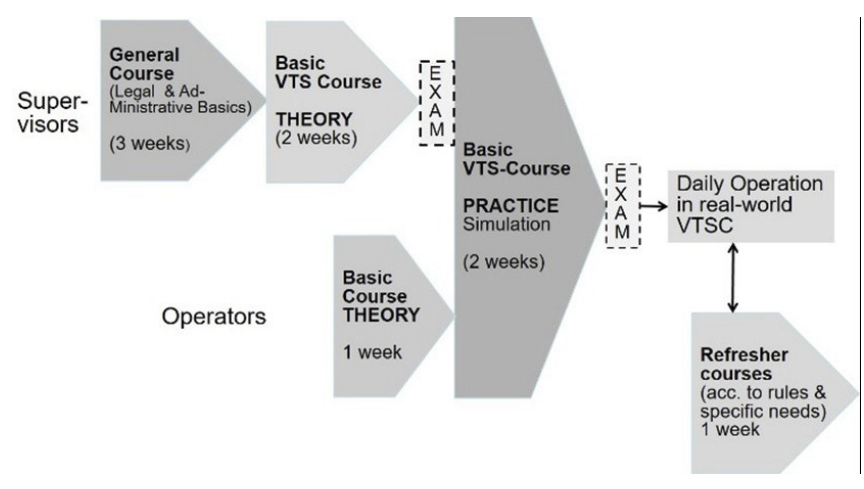

Figure 4: Training Scheme of VTS staff in Germany (graphic adapted from [20]). 
addition, the VTS staff has to take part in VTS Supervisor Training of $V-103 / 2$ for upgrading a level into the supervisor. The training scheme of VTS staff in Germany could be seen in Figure 4.

\section{Summary and Outlook}

Comparative empirical studies of Indonesian Merak VTS in the Sunda Strait and the German VTS in Warnemünde monitoring vessel traffic in the South Baltic Sea have been carried out, in order to identify potentials for improvement and further development of VTS operation to address the challenges of increasing traffic density and ship dimensions. The focus of the studies was the technical and organizational aspects of VTS operations.

The main outcomes of the studies are the implementation level of Merak VTS in context of human element and administrative works is sufficiently in compliance with IMO Resolution A.857(20) according to expert opinions. However, the technical aspects showed lower level of compliance with IALA Guideline 1111. The provided services of Merak VTS and Warnemünde VTS Centre are in accordance with the need of each navigational area connecting the economic and cultural regions. The Merak VTS staff were trained according to IALA VTS 103 modules, but it has not been fully obtained by all personnel yet. The period of trainings as has been provided by the Warnemünde VTS Centre is significantly increasing the skills and knowledge of personnel. There is some lack of power to enforce regulations effectively and can be enhanced. From the outcome of the studies it seems to be necessary to adapt functionalities for better and broader monitoring and reporting.

The study very well recognizes that the comparison is made between a longterm operating VTS in Germany, which has undergone several phases of optimization during its course of existence. In comparison to this, Merak VTS is at an earlier stage of operation. Therefore, the recommendations are derived based on the research carried out so far, and none of the following recommendations are meant as criticism but intended to contribute to the potential improvement of existing VTS operation in the Sunda Strait.

- The results of the study suggest further assessment of the human element aspects in Merak VTS. The planning and establishing of systematic training and education for all categories of personnel will be beneficial for all the involved parties, which are VTS operators, domestic and international ships, as well as waterway and shipping administrations. It might also be beneficial to have additional employment of Merak VTS staff, especially the VTSO, to increase productivity and provide a better working environment. The higher employment also has to be in line with the appropriate training provided by IALA VTS 103 module course for the operator doing the required tasks, which may help resulted in a further contribution to maritime safety.

The integrated collaboration of VTS and ferry companies seemingly may utilize the system of monitoring and communication, not only to manage the traffic and the vessels in the time of accidents but also to take prior action in preventing potential accidents from happening and maybe even contribute to efficient traffic flow without delays and supporting navigation regimes that minimize emissions from ships.

For future developments, a higher level of services from Merak VTS seems to be possible and is recommended. Since TSS and mandatory SRS have been adopted by IMO, upgrading the services into NAS and TOS would greatly support the system's implementation.

The study further recommends more regular communication between adjacent VTSs, such as Merak VTS with Panjang VTS, to significantly increase monitoring and reporting across the area. The distribution of information is also recommended to be done, for example, the automatically integrated database between adjacent VTSs or even all VTSs in Indonesia.

The provided technical equipment provides already enhanced monitoring functions, such as for triggering warning for potential collisions or groundings. Extending the services and training of staff on how to make use of such functions 
efficiently may also contribute to improve future

VTS operation of Merak VTS and increase

maritime safety.

The results gained from the baseline studies indicate that there is room for improvement. It is expected that the technical and technological developments in the field of shore-based monitoring, including e-Navigation and rapid digitalization, as well as more enhanced traffic organization, will soon allow or even requiring more proactive traffic control in the sense of managing and coordinating vessel traffic. Consequently, operational procedures need to be further developed, and shore-based operators will have to be trained adequately to be well prepared for addressing their complex tasks to ensure the safety and efficiency of maritime transportation.

\section{ACKNOWLEDGEMENTS}

The research work and the presented results were mainly carried out by authors and supported by Hochschule Wismar and Institut Teknologi Sepuluh Nopember. A big special thanks goes to the German Waterway and Shipping Administration, the Indonesian Navigation District Office Class I of Tanjung Priok and to all operators and technicians who supported the observations and provided input through questionnaires and interviews.

\section{REFERENCES}

[1] George R., Ninety Percent of Everything: Inside Shipping, the Invisible Industry That Puts Clothes on Your Back, Gas in Your Car, and Food on Your Plate, Metropolitan Books/Henry Holt and Co., USA, 2013.

[2] United Nations Conference on Trade and Development, Review of Maritime Transport 2018, United Nations, 2018.

[3] Vessel Traffic Services Manual Edition 6, IALA, 2016.

[4] Guidelines for Vessel Traffic Services, IMO Resolution A.857(20) Assem. 20th Sess. Agenda item 9, 1997.

[5] Praetorius G., "Vessel Traffic Service (VTS): a maritime information service or traffic control system?", Ph.D. Thesis, Chalmers University of Technology, Sweden, 2014.

Baldauf M., Fischer S., Kitada M., Mehdi R.A., AlQuhali M.A. and Fiorini M., "Merging conventionally navigating ships and MASS merging VTS, FOC, and SCC?", TransNav, Marine Navigation and Safety of Sea Transportation, vol. 13, no.3, pp.495-501, 2019.

[7] Southall T., "Seminar on the Revision of IMO Resolution A.857(20) Guidelines for Vessel Traffic Services", International Association of Marine Aids to Navigation and Lighthouse Authorities, 2019.

[8] Aylward K., Johannesson A., Weber R., Mackinnon S.N. and Lundh M., "An evaluation of low-level automation navigation functions upon vessel traffic services work practices", Springer Publishing, WMU Journal of Maritime Affairs, pp. 1-23, 2020.

[9] IMO, "NCSR 6/3/3 Routeing Measures and Mandatory Ship Reporting Systems", in NCSR 6th session Agenda item 3, Online:

http://docs.imo.org/, 2017.

[10] HELCOM, Baltic Sea Clean Shipping Guide 2016, Helsinki Commission, Finland, 2016. Kuma J.A., "Vessel traffic service as a maritime security tool: vessel traffic management information systems (VTMIS) in Ghana", Dissertation, World Maritime University, Sweden, 2015.

[12] Hydrography and Oceanography Centre, Indonesian Navy Chart IDN400170: Sunda Strait Merak to Bakauheni, Pushidrosal Sales and Distribution Units, Indonesia, 2018.

[13] The Enforcement Standard Operational Procedures for Merak Vessel Traffic Services (VTS), Directorate General of Sea Transportation of the Republic of Indonesia Decree Number NV. 101/1/8/ DJPL.15 (articl in Bahasa), 2015. National Transportation Safety Committee (KNKT), Accident Reports, Online Available: http:// knkt.dephub.go.id/knkt/ntsc_maritime/ martime.htm, 2020.

[15] VTS Guide Germany Edition 12th, Federal Maritime and Hydrographic Agency of Germany 
BSH-No. 2011, pp.88-105, 2018.

[16] Sunaryo S., Priadi A.A. and Tjahjono T., "Implementation of traffic separation scheme for preventing accidents on the Sunda Strait", International Journal of Technology, vol.6, no.6, 2015.

[17] IMO, "NCSR 5/INF.24 Routeing Measures and Mandatory Ship Reporting Systems", in NCSR 5th session Agenda item 3, Online Available: http:// docs.imo.org/, 2017.

[18] Preparation of Operational and Technical Performance Requirements for VTS Systems, IALA Guideline 1111, 2015.

[19] The Maritime Telecommunication, Ministry of Transportation of the Republic of Indonesia Number PM 26 of the Year 2011 (article in Bahasa), 2011.

[20] Claresta G., "Optimization vessel traffic service - a comparing case study of Merak VTS in Sunda Strait Indonesia and Warnemünde VTS in Baltic Sea Germany", B.Eng. Thesis, Hochschule Wismar University of Applied Sciences - Institut Teknologi Sepuluh Nopember, Germany - Indonesia, 2019.

[21] Kitada M., Baldauf M., Mannov A., Svendsen P.A., Baumler R., Schröder-Hinrichs J.U., Dalaklis D., Fonseca T., Shi X. and Lagdami K., "Command of vessels in the era of digitalization", Springer Publishing, Advances in Intelligent Systems and Computing, vol.783, pp.339-350, 2019.

[22] Sari N.K., Baldauf M. and Kitada M., "E-Navigation or autonomous navigation - quo vadis?", in Proceedings of 2018 MASTIC 1st Maritime Safety International Conference, pp.46-53, 2018.

[23] Baldauf M., Kitada M. and Mehdi R., "Enavigation, digitalization and unmanned ships: challenges for future maritime education and training", in Proceedings of 2018 INTED 12th International Technology, Education and Development Conference, pp.9525-9530, 2018. 